\title{
Demand Response for Smart Home: An Evaluation from an End-User's Perspective Based on a High Resolution Power Demand Model
}

\author{
Efrain Bernal, Mustafa Süslü, Jian Xie
}

\begin{abstract}
This study investigates customer response to demand response with direct load control at the smart home by implementing home energy management HEM algorithm. An economical evaluation is done to estimated the benefices from the user's perspective. Initially, this study outlines the development of a high-resolution smart home power demand model with the trends in photovoltaic PV, home automation systems, efficient appliances and battery support, to estimate the potential impacts of demand response programs on the residential load profiles. Finally, the results show highly annual and daily variations on the demand load profile for fixed tariff scenarios up $44 \%$ with respect to the current demand profile. Consequently, in the case of TOU rate tariff scenarios, a critical variation for the peak and off-peak transition period was found. This variation goes up $64 \%$ with respect to the current demand profile pattern and $80 \%$ with respect to the smart home demand profile pattern. Additionally in case of TOU tariff, the end-users income is much higher than that of fixed tariff. For small household only using solar panel with home automation system the net cumulative income surpluses, but using battery doesn't reflect economically favorable conditions. In 4 or more person household, using $2 \mathrm{kWh}$ battery with automations, the net income is $41 \%$ higher than using only PV. Furthermore, comparing it with PV and automations of $100 \%$, the net income increases other $15 \%$.
\end{abstract}

Keywords - home automation, HEM, smart home, demand response.

\section{Introduction}

This increasing electricity price, scarcity of fuels, green energy technology and as long as world's environments concern, all these end up vastly increase of renewable energy in recent years over the whole world. Among them Germany is the pioneer of using renewable energy sources especially photovoltaic PV. It is very common that in winter season power supply is not enough from the PV and results needing a lot of power from the Grid or other sources to cover up the required energy of the household. Meanwhile in summer season a massive amount of power is generated from the PV and it overwhelms over the needs of household in day time. The excess power can't be wasted, so the way is to supply the excess power to the grid.

MSc. Efrain Bernal Alzate

Institute of energy conversion and storage EWS, University ULM, Germany

Dr. Mustafa Süslü

Institute of energy conversion and storage EWS, University ULM,

Germany

Prof. Dr-Ing Jian Xie

Institute of energy conversion and storage EWS, University ULM, Germany
Therefore, to enlarge the service of the current electrical distribution grid and to reduce the need for grid expansion, utilities are promoting demand response programs that offer customers financial incentive to shift some demand to offpeak times. From the user perspective, it is not clear, if these programs in combination with automation technologies, are rentable or not. At this aim, a high resolution power demand model was initially developed [25] and it is used to estimated the economical benefic of demand response programs in Germany from the user's perspective. The model presented in this paper improves significantly the modeling of energy consumption and demand side analysis proposed in [2-7,21], allowing the simulation of the effects of efficiency improvements on appliances, different levels of photovoltaic/battery penetration, with a home energy management HEM algorithm to model a high-resolution smart home power demand over different demand response scenarios. A detailed presentation of the model is given in Section II. In Section III, the power demand setup and the HEM algorithm are presented. The economical evaluation for future different scenarios is described in Section IV. The results are discussed in Section $\mathrm{V}$ and conclusions are drawn in section VI.

\section{Smart Home Model}

The methodology for the modeling of a high resolved smart home profile can be summarized as follows.

\section{A. High Resolution Model}

The structure of the model is presented in Fig.1. This is a bottom-up modeling technique $[3,4]$, that generates synthetic activity patterns for each household member which are then converted into power demand for the household, taking into account the effects of technology improvements, automation algorithms and other smart home requirements for the construction of the load model. On the left side of the diagram, the reference load is established from a report on energy use of households in Germany [9] as well as an annual report of the demand load profile [10]. In this part the load model is calibrated to represent a German household. On the right side of the diagram, the considerations and trends for the different future scenarios are analyzed and brought to the model generator to create the smart home's load profile. This procedure can be repeated for an arbitrary number of households, to create a larger set of demand data.

\section{в. Generation of synthetic activity patterns}

Modeling individual's behavior is a complex task, due to the stochastic nature of the activities performed. This model uses non-homogeneous Markov chain to model occupant 


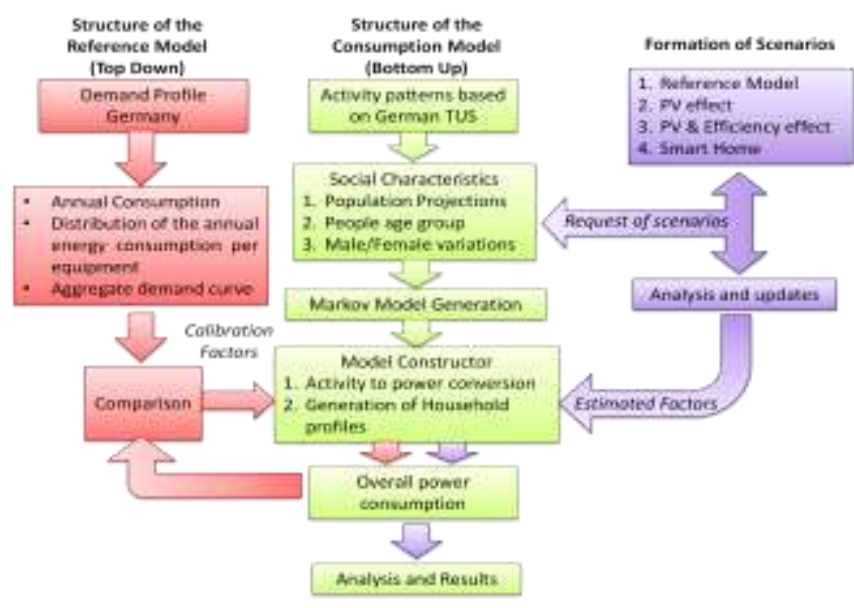

Fig. 1. Flow chart of the methodology for the high-resolution smart home power demand modeling.

behavior and predict the associated energy consumption. In order to estimate the transition probability matrices used in the behavioral Markov chain model, detailed time usage records are required. In this case, a German time use survey (TUS) [11] is used to determine the vectors of probabilities for the transition probability matrices for the Markov chain as:

$$
X(k)=\left(x_{l}(k), . ., x_{n}(k)\right)^{T}
$$

Where $x_{i}(k)$ is the probability that activity number $i$ will be performed in time interval number $k$ with $i=1 \ldots 13$. Fig. $2 \mathrm{a}$ shows an example of this individual's behavior probability for the different activities for a German household. The probability of each activity group is shown as length relative to the ordinate for each hour of the day. In Fig.2b is presented the activities of a 3 person household for consecutively 2 days generated by the Markov chain model constructor. In each of the hour of a day any of the 13 activities took place by 3 persons. Sometimes same activity like sleeping occurred for 2 persons at the same time. As an example of the activity washing which occurred only one time by one person in between 3 persons in this total 2 days.

\section{Activity-to-power conversion}

There may be multiple appliances assigned to a single activity. For example, cooking as a basic activity can involve numerous appliances such microwave, ovens, stoves, kettles, etc. Widén [6] found that a simple but sufficient accurate solution is to assume a constant power demand during the cooking activity. Each appliance in the model is associated with one of three an activity-to-power conversion schemes: Constant demand during the activity, a variable duty-cycle demand that starts with the activity and sharing scheme. When an appliance is shared, the power demand is determined from the combined pattern. The approach is similar as in $[5,8,13,19]$ but load patterns are combined with the representation of standby as in [6].

Fig.2c shows the amount of energy per day for each activity as the load demand profile for the same 3 persons household presented in Fig 2.b. In the time of 20 to 24 hour of the day there occurred only sleeping and others activity by the 3 persons. But this two activity doesn't reflect any power, so power demand curve also reflects the same no power activity with only standby given power. For another example it can be observable that in between the hour of 36 and 37, in the activity curves represents the activity of cooking and computer which symbolize the highest power demand on that two days of approximately $2.2 \mathrm{kWh}$ in demand curve.

\section{Power Demand Setup}

In this section, the previously generated load profile, it is employed with PV and battery support to comply with the household energy management (HEM) system to evaluated the electrical and economical impacts for two demand response scenarios, as follows.

\section{A. Feed in Tariff}

The feed in tariff (FIT) is the price to sell the energy to the Grid [21]. The German Renewable Energy Act (EEG) fixed the level of the FIT for all the energy sources and in case of solar power, it's getting the priority. This tariff is valid for 20 years from the installation of the plants. Just $6 / 7$ years before the tariff was so higher for the investors. But recently the situation is changed. From the beginning of 2012 the FIT of household gets grid parity which is a significant moment. Accordingly June 2014, the tariff is in between 9.01 and 13.01 e-cents/kWh for different size of plants who will install plant now for next 20 years [15]. As the present domestic electricity price is almost 29 cents/kWh, so FIT is much lower comparing that. Those

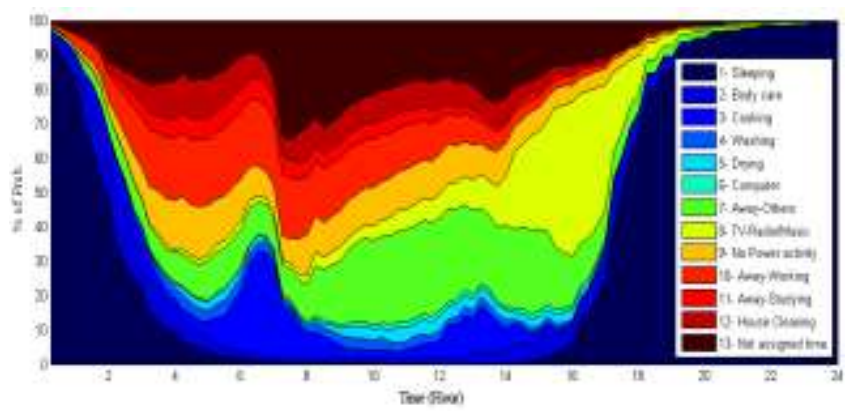

a.

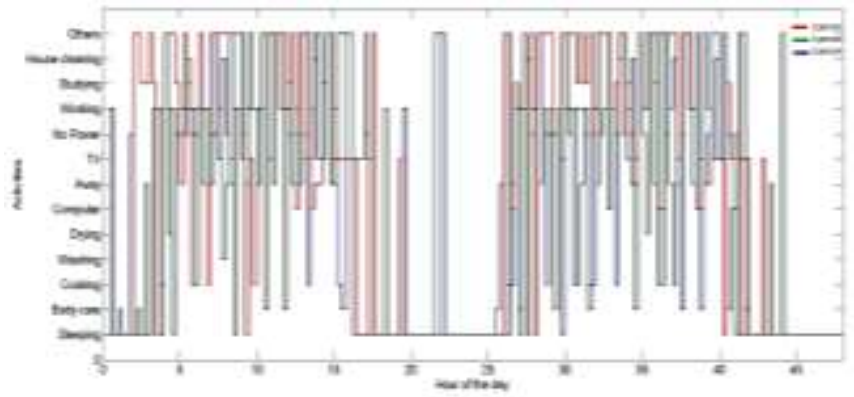

b

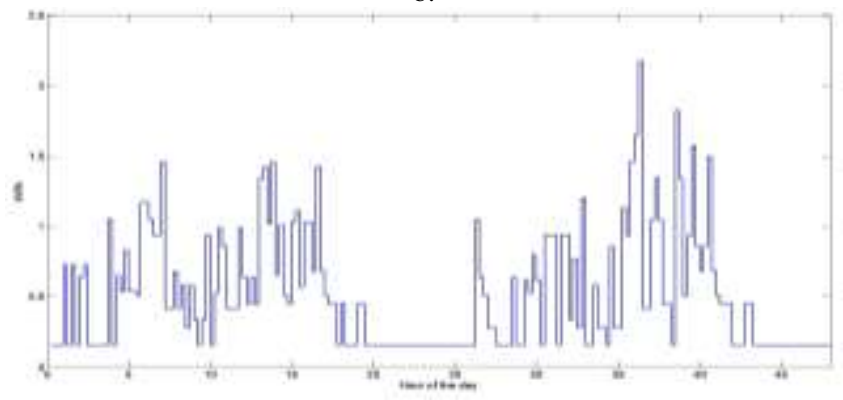

c.

Fig. 2. Generation of household load profile. a. Example of attractors for the Markov chain model. b. Resultant patterns for 3 persons in a household for two days. c. Generated demand for the modeled 3-Persons Household. 
who consume self-generated energy cannot be comparable with the FIT as profit. Now self consumption is the most profitable from solar panel. The average feed in tariff for PV is showing the present tariff which mainly depends on previously activated FIT almost 15 years before and after running for 20 years. The average feed in tariff is now going down significantly. Though the present FIT is much lower and its which effect will be observed after $15 / 20$ years later.

\section{B. Time of Use Rate}

Instead of a single flat rate for energy use, time of use (TOU) rate is used in different countries in different states [12]. The main reason behind to use the TOU tariff is to shave the peak demand of energy use. Customers are strongly encouraged to use the benefit of TOU [14]. Normally in off peak time the electricity price is set to lower the cost to encourage people to use energy on that time. Thus people can reduce their electricity bill significantly. TOU tariff could be in several periods. Here in the model it is used only two levels price to check the effect of TOU for the customer level [20]. It is to remember that the current flat rate of electricity is used only for simulating the current years. But for future the electricity price will be much higher. The forecasted value from IBESA [4] is used to simulate the future energy scenario. But it is assumed that the TOU rate will remain same as: Flat rate $(6 \mathrm{am}-11 \mathrm{pm})$ 30 cents/kWh and TOU rate (11pm-6am) 20cents/kWh.

\section{HEM algorithm}

By using the different tariff types and automation we can construct a HEM algorithm for a Smart Home [2]." The demand management model architecture is shown in the figure 4. Previously built load profile is used as a data input in this model with photovoltaic power generation over the whole year with every 15 minute time steps like before. The SOC is also included as an input of the model. The initial SOC is set to $80 \%$. The model developed three seasons load management scenario as before. To create the model every time the load and PV generation is compared with each other. Then the first priority is given to the PV to supply the load. When there is a shortage of power supply occurs, at first the model constructor will look for battery supply, if it doesn't full fill then it will take power from the grid.

For charging the battery it is always preferable to take power from the PV. Only if there is any TOU tariff working, then the battery might charge during that period to support the following high price energy period. Charging of battery from the grid has given some limitations depending on the seasons. In summer time enough photovoltaic is available, so battery charging limitation is set to $30 \%$ from the grid, for winter case it is set to full charging from the grid to use the benefit of TOU as there is not enough power generation from the photovoltaic in day time also.

Finally, in the case of shoulder season; the limit is set to a moderate value of $50 \%$. In case of fixed tariff there is no criterion to charge the battery from the Grid as by there is no mean to charge from grid. When PV generation power is much higher than load power then firstly it will try to charge the battery and then the surplus energy will be fed in to the grid

\section{Economical Evaluation}

Previously described HEM system finds a set of feasible solution for different types of household based on load profile characteristics, PV plant and energy storage. The target is to minimize the electricity costs in household. This study made an economical evaluation of the previously built model, comparison of costs \& benefits from an end-user's perspective and the impacts into the load profile as follows.

\section{A. Cost calculation}

For generating the system cost the following methods have taken into accounts according to [16]. When the model is only for a household with the Solar panel then the cost is include with only the first part of this section as:

$$
P V \text { Cost }=C_{\text {solar }}+C_{\text {inverter }}+C_{\text {om }}+C_{\text {insurage }}+C_{\text {interest }}+C_{\text {inst }}(1)
$$

Where $C_{\text {solar }}, C_{\text {inverter }}, C_{\text {om }}, C_{\text {insurage }}, C_{\text {interest }}$ and $C_{\text {inst }}$ are the costs of solar, inverter, operation and maintenance (O\&M), insurance, bank interest for loan, and installation cost of solar, respectively. The basic cost of battery are calculated as:

$$
\text { Battery Cost }=C_{\text {bat }}+C_{\text {inverter }}+C_{\text {batt_setup }}+C_{\text {replacement }}(2)
$$

Where $C_{\text {bat }}, C_{\text {inverter, }} C_{\text {batt_setup }}$ and $C_{\text {replacement }}$ are the costs of battery, battery inverter, battery installation, and replacement cost respectively. For home automation setup there are additional cost have been included. All the cost sare divided into two parts. One is the setup cost and another one is the recurring cost, O\&M cost, insurance, interest, bank debt. Setup cost is funded by own and rest is by bank loan. The data for the calculation are given in the table 1 .

TABLE I

\begin{tabular}{|c|c|}
\multicolumn{2}{|c|}{ AlLOCATIONS OF COST } \\
\hline Name of Cost. & Cost (€) \\
\hline Solar panel & 6489 \\
\hline Solar panel Setup & 2000 \\
\hline Solar Inverter & 1873 \\
\hline Own funds & 4415 \\
\hline Loan Amount & 13246 \\
\hline Battery installation & 2000 \\
\hline Battery inverter & 1300 \\
\hline Total Battery & 5300 \\
\hline Home Automation & 2000 \\
\hline
\end{tabular}

All the data were collected according to [10, 15, 23] for a German Smart Home. An example of the allocations of costs, taking account all the data mentioned previously, are given in the table 2 . In this case the model is taken for 4 person household with $2 \mathrm{kWh}$ of battery including $100 \%$ automation at home.

\section{v. Simulation Results}

The model can produce the projections of household scenarios till 2050 which also reflects the changes in people's behavior of in future Germany. The population will age increasingly and as detail.

Here we will integrate the results in respect with the demand of amount of energy and economical aspects which describes at the end rational behavior of the end users. 
TABLE II

SUMMERY OF DATA THAT USED FOR DIFFERENT SCENARIOS

\begin{tabular}{|c|c|}
\hline Single panet cost $(\epsilon)$ & 309 \\
\hline Number of Panets & 21 \\
\hline System size (kWp) & 5 \\
\hline OEM cost in first year $(\epsilon)$ & 175 \\
\hline Life time of solar panel (year) & 25 \\
\hline OleM cost increases per year & $2 \%$ \\
\hline Enverter cost (6) & 1873 \\
\hline Installation cost $(\theta)$ & 2000 \\
\hline Feed in Tariff $(E / \mathrm{kWh})$ for first 20 years & 0.13 \\
\hline Feed in Tarit after 20 years $(\ell / \mathrm{kWh})$ & 0.10 \\
\hline Insurance (\$ of setup cost) & $0.50 \%$ \\
\hline Insurance fnflation rate & $2 \%$ \\
\hline Own funds & $25 \%$ of total installation cost \\
\hline Loan Amount & $75 \%$ of total installation cost \\
\hline Bank Interest rate & $4 \%$ \\
\hline Lithium Ion Battery cost ( $\mathrm{E} / \mathrm{kWh})$ & 600 \\
\hline Replacement of Battery cost $(\Theta / \mathrm{kWh})$ & 400 \\
\hline Battery lifetime (year) & 11 \\
\hline Battery Inverter (e) & $1300 / 1815$ \\
\hline Battery Capacity (kWh) & $2 / 5$ \\
\hline Installation cost ( $(\varepsilon)$ & 2000 \\
\hline Home Automatson cost ( $\varepsilon$ ) & $\begin{array}{l}1000 \text { (40\% automation) and } 2000 \\
(100 \% \text { automation) }\end{array}$ \\
\hline
\end{tabular}

\section{A. Smart Home with HEM algorithm}

As the model is able to reproduce the power activity patterns of individual household members, then the energy consumed by each household member is associated with a home appliance to generate the electricity demand of a single household consisting of multiple individuals. Additionally, in this part, the model has been enhanced with a HEM algorithm as follows.

1) Seasonal variations: In the figure $5 \mathrm{a}$ it is shown the load management for the shoulder season. In this case a $5 \mathrm{kWh}$ battery is used with TOU tariff.

In this shoulder season charging from the grid is moderate to support the load after the TOU period when the electricity price is much higher. The PV generation is also medium. In summer season the PV supplies to the grid is much higher than the shoulder season and in winter it is not visible either. The generation of PV is much lower than other seasons and battery taking much more charge from the grid in the TOU period to support the load in the morning, thus how the TOU tariff can be utilized through the usage of battery.

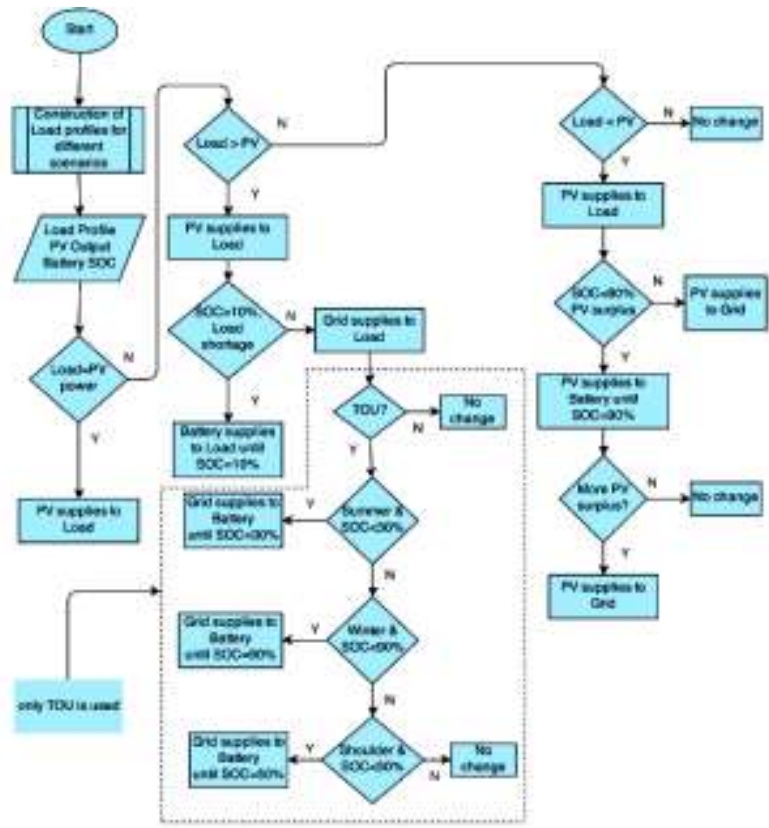

Fig.3. Flow chart of the proposed load management (HEM) algorithm.
2) Integrating photovoltaic $(P V)$ : Germany's goal is to increase the share of renewable energy to more than $80 \%$ by 2050 [5]. Another study describes that it is technically possible to generate all power renewably by the date. A recent study of PHI which has high penetrations of PV shows that the inverters have very good influence to the unity power factor and keeping the current balance on phases. So it is obvious to include the high penetration of PV into the model. Fraunhofer ISE predicts that the share of PV power will be $30 \%$ of energy production in Germany by 2050 [5]. Taking this into account a calibration factor is used into the model to include and project the PV penetration to the household which increases by the years.

3) Effect of Automation: Here the difference of reductions in load profiles in automation case also visible and leads to more PV supplies to the grid like before. also remarkable to see that the use of automations leads to reductions in load profiles and also the battery leads to support more load during the night time when there is no PV power which will reduce the electricity price significantly. All the cases are with fixed tariff that results no charging of battery from the grid.

4) Battery analysis: Because of high penetration of photovoltaic power the significance of the battery is not so much readable in day time. But in the night time the battery supports the load. When the battery capacity is higher than the battery support is bigger as usual. In day time the battery charges from the PV depending on the capacity. Bigger the capacity higher the self consumption from PV and saving money of grid electricity cost. Because selling to the grid is not cost effective now a day. In a winter day the effect of battery is more visible. Shortage of PV supply, inadequate generation of PV leads instability to the load management that can be compensated through the battery. In the TOU period battery charges up full and thus supports the load in other time. But in case of lower capacity, the battery isn't able to support the load a lot.

5) Effect of Different types of Tariff: Figure 5b and 5c are describing the difference between fixed tariff and TOU tariff in load management system. Because of lower PV
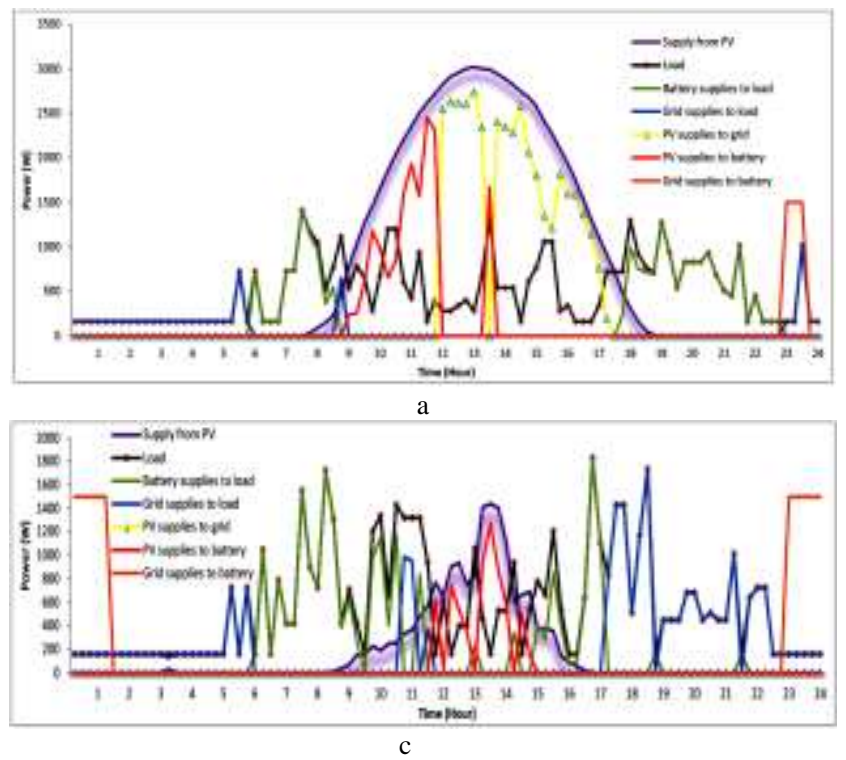

Fig. 4. Comparison of different types of load management scenarios. a Load management with $2 \mathrm{kWh}$ battery in a summer day. c. Load management with $2 \mathrm{kWh}$ battery and TOU tariff in a winter day 
supply battery needs to be charged from the grid in TOU period and support the load in the morning when TOU is not working and that leads to saving money. Whereas in fixed tariff system there is no option of charging from the grid so battery cannot able to support the load in morning time and the price of electricity gets higher.

\section{B. Aggregated households demand}

In this section previously built all the individual households, they are added to get the aggregated average demand load profile from the grid. With using of different scenarios the demand load from the grid decreases a lot. Figure 6 is presented with the variations of load demand for different scenarios with respect to the demand profile of reference scenario. Model reference is the projected load profile of 2050 without any automations or any other effects. From the model reference all other demand profile is deducted to know the variations of the load profile in the whole day. From the figure it can be observable that in case of TOU tariff the load profile always has the positive value in the TOU period that is in night time. Because of using charge from the grid in that period grid support a lot to the battery. In that time the price of the electricity though is not so much reduced but battery charges a lot because of the TOU tariff. Taking the charges in that period battery supports in morning time when the electricity price is higher comparatively to the TOU tariff. Thanks to the energy storage system for the reduction in the demand profile a lot in peak hour. Using the current demand daily profile for residential load in Bavaria-Germany reported by [24] as normalized reference model, the analysis undertaken in this study reveals that relative penetration of smart homes can cause an elevated variation on the daily demand profile. For fixed tariff scenarios, the variation on the daily demand profile was up $44 \%$ with respect to the current demand profile. Consequently, in the case of TOU rate tariff scenarios, a critical variation for the peak and off-peak transition period was found. This variation goes up $64 \%$ with respect to the current demand profile pattern and $80 \%$ with respect to the smart home demand profile pattern. This represents a potential power and voltage rise in LV distribution networks, and as result, the stability and performance of the actual voltage control methods have to be evaluated electricity price is set to lower the cost to

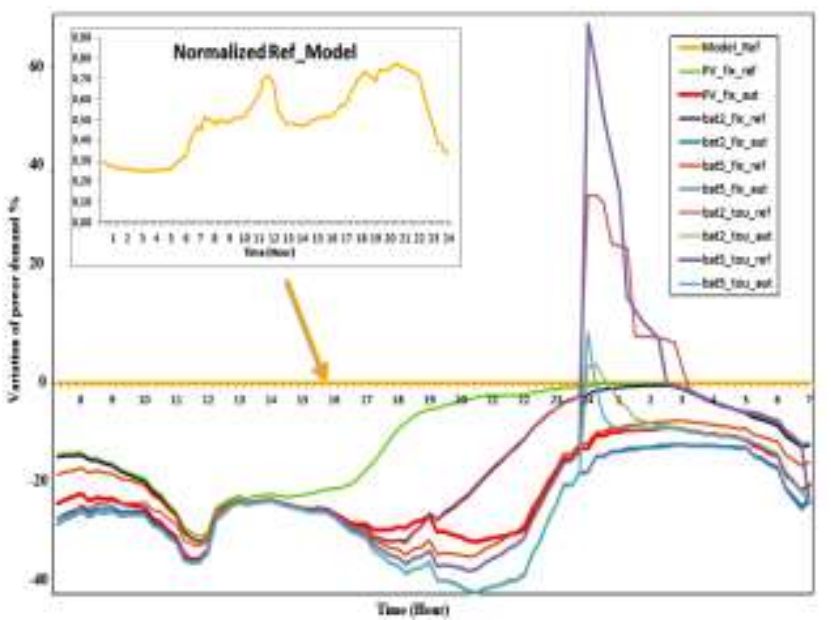

Fig. 5. Projected demand profile variation in a summer day for the combination of different scenarios: a reference scenario with PV, a reference scenario with PV and $100 \%$ automations, $2 \mathrm{kWh}$ or $5 \mathrm{kWh}$ battery support, and fix tariff or TOU rate tariff
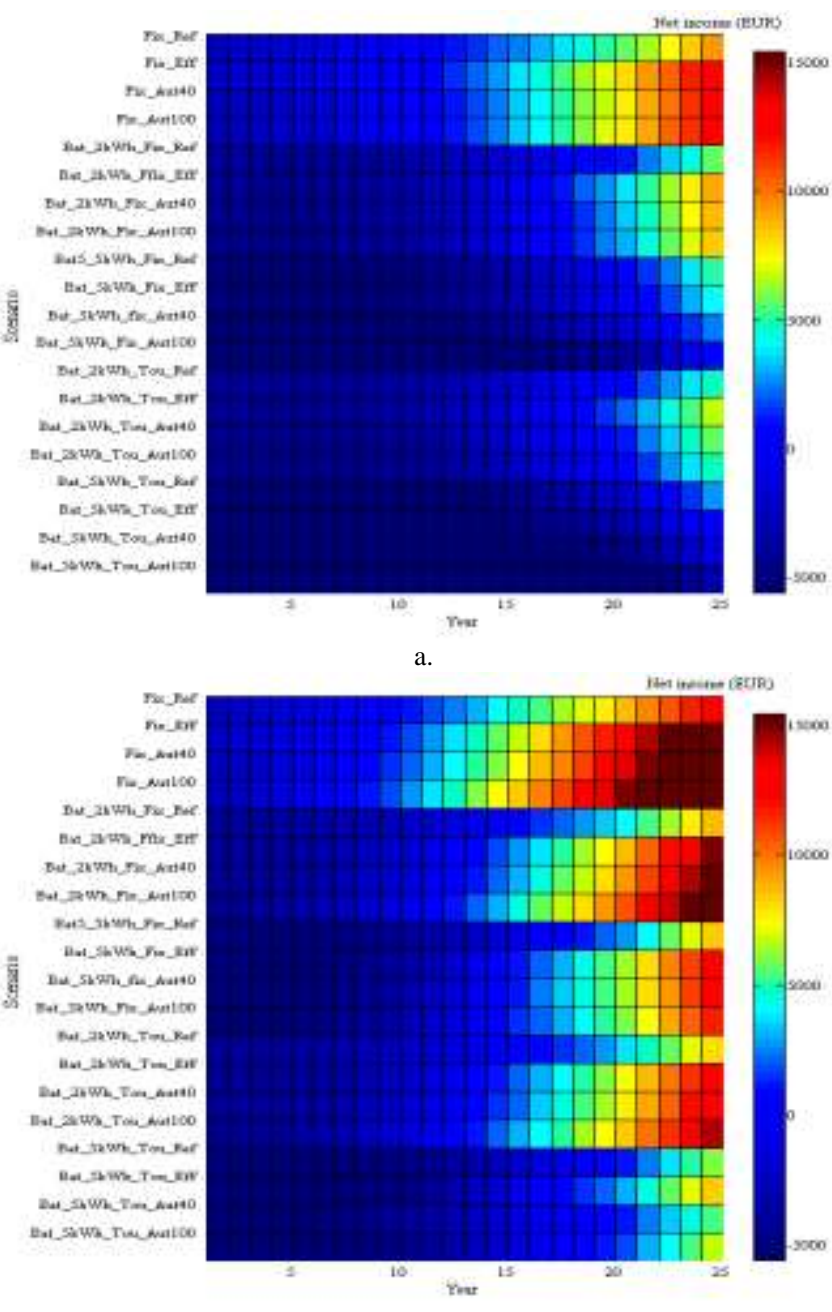

b.

Fig. 6. Net income of different scenarios. a. Net income for a 2 per. Household b. Net income for a 5 per. Household

encourage people to use energy on that time. Thus people can reduce their electricity bill significantly. TOU tariff could be in several periods. Here in the model it is used

\section{Users Economical Perspective}

Instead In the figure 6 presented the overview of net income of all the cases for 5 different households. In this case the cumulative net income is calculated deducting the investment value at the beginning. For automation scenarios the saving price of grid electricity cost is also included comparing with the reference case. The reference case is taken as the model with only solar when a fixed tariff is using without any automations or efficiency factor that represents the real behavior of households.

For 1 person household it is extractable that only using solar panel the net cumulative income surpluses the value of their own reference cases. In all other case with battery don't shows effective net income compared to reference case. Because of few numbers of persons in a household using battery doesn't reflect economically stable conditions. From 3 persons household using battery started to gaining surplus net income than the reference case. Here only $2 \mathrm{kWh}$ batteries gaining the net positive value. But in case of $5 \mathrm{kWh}$ batteries still doesn't show any reflection of surplus net income than reference case. 
In 5 persons household using $2 \mathrm{kWh}$ battery with fixed tariff starts to reflect more net income compared to reference case. Using the $100 \%$ automation in $2 \mathrm{kWh}$ battery reflects $41 \%$ more net income than the reference solar case. But using only solar and efficiency or automations still shows more net income than that of using battery. In TOU tariff it is not reflecting surplus income than the reference case. When using TOU tariff the battery normally charges in the night period from the grid, and support the load in day time. But in that case sometimes battery does not charge more from PV which effect to the net income. As more consumption from the PV gives more income. $5 \mathrm{kWh}$ batteries still show negative. But comparing with Solar with automations of $100 \%$ shows $15 \%$ less income. In more person household though using battery shows positive cumulative income with using automations. But none of the case it doesn't comparable with the same case with only using solar.

\section{vI. Conclusion}

A systematic approach for modeling high resolution smart home power demand and an economical evaluation of demand response programs in Germany from the user's perspective was developed.

The smart home interactions and impacts on the load profile for different PV penetration levels, with fixed tariff or TOU rate tariff and for different smart home setups was simulated and analyzed. The results show highly realistic patterns that capture daily and annual variations for the smart home profiles. Besides, the analysis undertaken in this study reveals that relative penetration of smart homes can cause an elevated variation in the daily demand profile up to $44 \%$ with respect to the current demand profile pattern for fixed tariff scenarios and instantaneous variation up $64 \%$ for TOU rate tariff scenarios.

Moreover, an economical evaluation of different scenarios shows a way to develop model for individual household depending on number of persons in a household. After a huge reduction of feed in tariff recently, only using solar panel still shows economically feasibility in all the cases. Using appropriate storage device in a household can return the investment though the net income still lag behind with only using solar panel, but in future with technological developments it will be a great option for the customers to maintain the demand load management and will reduce the pressure on grid

\section{References}

[1] Nakajima Tadahiro, Shigeyuki Hamori, "Change in consumer sensitivity to electricity prices in response to retail deregulation: A panel empirical analysis of the residential demand for electricity in the United States. From: Elsevier, Energy Policy 38 (2010) 2470-2476.

[2] Yoon Hoon Ji, Bladick R., Novoselac A. "Demand Response for residential buildings based on dynaimc price of electricity". From: Elsevier, Energy and Building 80(2014)531-541.

[3] Chrysopoulos A., Diou C., Symeonidis A.L., Mitkas P.A. "Bottom-up modeling of small-scale energy consumers for effective Demand Response Applications. From: Elsevier, Engineering Applications of Artificial Intelligence 35 (2014) 299-315.

[4] Ammon, Martin. Electricity Storage PV: Current Status Market Overview Germany. June 2013
[5] Richardson, I., Thomson, M., Infield, D. "A high-resolution domestic building occupancy model for energy demand simulations" Energy and Buildings, 40, pp. 1560-1566, 2008.

[6] Widén, J., Wäckelgård, E. "A high-resolution stochastic model of domestic activity patterns and electricity demand "Applied Energy, 87, pp. 1880-1892. 2010.

[7] Muratori, M., Roberts, M.C., Sioshansi, R., Marano, V., “A highly resolved modeling technique to simulate residential power demand", AppliedEnergy 107 PP. 465 - 473, 2013

[8] Soares A., Gomes A., Antunes C.H. "Categorization of residential electricity consumption as a basis for the assessment of the impacts of demand response actions" Elsevier, Reneable and Sustainable Energy Reviews 30 (2014) 490-503.

[9] Federal Statistical Office of Germany, "German Statistical Yearbook 2012", Chapter 2. March 2013

[10] ISE, Fraunhofer institut for solar energy. "Recent facts about photovoltaics in Germany“. 2014

[11] Ehling, M., Erlend, H. and Kahle, I."Erhebungsdesign der Zeitbudgeterhebung 2001/2002", Statistisches Bundesamt Wirtschaft und Statistik, , 427-436, 2002.

[12] Muratori M., Schuelke-Leech B.-A., Rizzoni G. " Role of residential demand response in modern electricty markets". From: Reneable and Sustainable Energy Reviews 33 (2014) 546-553.

[13] Pengwei D., Ning L., "Appliance Commitment for Household Load Scheduling". From IEEE Transactions on Smart Grid, Vol. 2, No.2, june 2011.

[14] Thorsnes P., Williams J., Lawson R., "Consumer Responses to time varying pricesfor electricity". From: Energy Policy 49 (2012) 552561 .

[15] ISE, Fraunhofer institut for solar energy. "Levelized cost ofelectricity renewable energy technologies". November 2013

[16] MAYER, Analytics: website based analytical company. - URL http://mayeranalytics.com/,http://pvcalc.org/pvcalc

[17] [17] Rajkumar G., Priya S., Marimuthu C.N., "Design and Implementation of Home Energy Management with Demand Response For Smart Home" From: Interantional Journal of VLSI and Embedded systems-IJVES Vol.5 Article 02227, February 2014.

[18] [18] Ifland M., Exner N., Westermann D. "Influencing Domestic Customers' Market Behavior with Time Flexible Tariffs. From IEE PES Innovative Smart Grid Technologies Europe (ISGT Europe), Berlin

[19] Balijepali M., Pradhan V., Khaparde S.A. "Review of Demand Response under Smart grid Paradigm ". From: IEEE PES Innovative Smart Grid Technologies- India 2011.

[20] Torriti J. "The significance of occupancy steadiness in residential consumer response to Time-of-Use pricing: Evidence from stochastic adjustment model. From Utilities Policy 27 (2013) 49-56.

[21] BARTUSCH C., WALLIN F., ODLARE M.,VASSILEVA I., WESTER L. : Introduction a demand-based electricity distribution tariff in the residential sector: Demand response and customer perception. From :School of Sustainable Development of Society and Technologgy, Mälardalen University, P.O. Box 883, SE-721 23 Västeras, Sweden

[22] GELLINGS, C.W.: Power/energy: Demand-side load management: The rising costof peak-demand power means that utilities must encourage customers to manage power usage. In: Spectrum, IEEE 18 (1981), Dec, Nr. 12, S. 49-52. - ISSN 0018-9235

[23] SCHLICK, Dr. T. ; HAGEMANN, Bernhard ; KRAMER, Michael ; GARRELFS,Jens ; RASSMANN, Alexander: Zukunftsfeld Energiespeicher, Marktpotenzialestandardisierter Lithium-IonenBatteriesysteme. $2012 . \quad-\quad$ URL http://www.rolandberger.de/media/pdf/Roland_Berger_Zukunftsfeld_ Energiespeicher_20120912.pdf

[24] [Measured daily profile for residential load in Bavaria-Germany reported by HOB E.ON Mitte. Available: http://www.eonmitte.com/admin/userimages/File/netz/Veroeffentlichu ngen/Strom/Standardlastprofile/2014/h0_10-13_g0-g6_bayern2014.zip

[25] E. Bernal, N. Mallick, and J. Xie. A high-resolution smart home power demand model and future impact on load profile in Germany. IEEE International Conference on Power \& Energy (PECON), Dec. 2014 